\title{
Near-room-temperature operation of an InAs/GaAs quantum-dot infrared photodetector
}

\author{
Shiang-Feng Tang, Shih-Yen Lin, and Si-Chen Lee \\ Department of Electrical Engineering, National Taiwan University, Taipei, Taiwan, Republic of China
}

(Received 21 August 2000; accepted for publication 15 February 2001)

\begin{abstract}
A ten-stacked self-assembled InAs/GaAs quantum-dot infrared photodetector operated in the 2.5-7 $\mu \mathrm{m}$ range by photovoltaic and photoconductive mixed-mode near-room-temperature operation $(\geqslant 250 \mathrm{~K})$ was demonstrated. The specific peak detectivity $D^{*}$ is $2.4 \times 10^{8} \mathrm{~cm} \mathrm{~Hz}^{1 / 2} / \mathrm{W}$ at $250 \mathrm{~K}$. The use of high-band-gap $\mathrm{Al}_{0.3} \mathrm{Ga}_{0.7} \mathrm{As}$ barriers at both sides of the InAs quantum-dot structure and the long carrier recombination time are the key factors responsible for its near-room-temperature operation. (C) 2001 American Institute of Physics. [DOI: 10.1063/1.1362201]
\end{abstract}

In the past few years, the AlGaAs/GaAs quantum-well infrared photodetector (QWIP) and the InAs/GaAs quantumdot infrared photodetector (QDIP) had been widely investigated due to their commercial and military applications. ${ }^{1-8}$ The most dramatic result of using the QDIP to detect midand far-infrared signals was its high-temperature performance. $^{6-8}$ The GaAs/(AlGa)As QWIP could rarely be operated beyond $100 \mathrm{~K},{ }^{1-5}$ however, the InAs/GaAs QDIP had been easily operated over $100 \mathrm{~K}^{6-8}$ In this letter, the characteristics of a self-assembled InAs/GaAs QDIP are presented. By clamping the InAs quantum-dot (QD) structure with two high-band-gap $\mathrm{Al}_{0.3} \mathrm{Ga}_{0.7} \mathrm{As}$ layers, the operation temperature of the QDIP is dramatically raised up to $250 \mathrm{~K}$ in the 2.5-7 $\mu \mathrm{m}$ range.

The self-assembled InAs quantum dots were grown on a (100) GaAs semi-insulating substrate in the StranskiKrastanov growth mode using solid-source molecular-beam epitaxy (MBE) under As-shutter-closed condition. The substrate temperature was kept at $510^{\circ} \mathrm{C}$ during $\mathrm{MBE}$ growth. The detector structure is of ten-stacked InAs quantum dots with $3 \mathrm{ML}$ coverage separated by a $30 \mathrm{~nm}$ undoped GaAs layer, where the $3 \mathrm{ML}$ InAs quantum dots are uniformly doped to $1 \times 10^{17} \mathrm{~cm}^{-3}$ (throughout the volume of the dots). According to the atomic-force microscope measurement, the dot density is around $4 \times 10^{10} \mathrm{~cm}^{-2}$, which implies that average five quantum dots contain one Si dopant. Two extra $\mathrm{Al}_{0.3} \mathrm{Ga}_{0.7} \mathrm{As}$ confining layers were grown on both sides of the ten-stacked QD structure to reduce the dark current and preserve the photoexcited carriers. 0.5 and $1 \mu \mathrm{m} \mathrm{GaAs} \mathrm{layers}$ with doping density $1 \times 10^{18} \mathrm{~cm}^{-3}$ were grown on top and bottom as the contact layers. The schematic device structure is shown in Fig. 1.

After growth, detectors with $100 \times 100 \mu \mathrm{m}^{2}$ size are fabricated. The current-voltage $(I-V)$ characteristics of the devices are measured by a HP4156B semiconductor parameter analyzer, and the spectral response was measured under an edge-coupling scheme with APD cryogenics and a PerkinElmer S2000 Fourier transform infrared spectroscope. A chopped black-body source at $1080 \mathrm{~K}$ is used to calibrate the absolute value of responsivity.

Figure 2 displays the temperature-dependent dark $I-V$ characteristics of the InAs/GaAs QDIP from 10 to $300 \mathrm{~K}$. The photocurrent measured at $10 \mathrm{~K}$ with the device illumi- nated from the background radiation is shown as a dotted line which is higher than the dark currents up to $250 \mathrm{~K}$ at external biases of $\pm 1 \mathrm{~V}$. This indicates that the backgroundlimited-performance temperature is $250 \mathrm{~K}$. Figures 3(a) and 3(b) show the temperature-dependent responsivity and peakspecific detectivity of the QDIP at zero bias, which gives direct evidence that this device can be operated in the photovoltaic (PV) mode. As shown in Fig. 3(b), the peakspecific detectivity is $2.4 \times 10^{8} \mathrm{~cm} \mathrm{~Hz}^{1 / 2} / \mathrm{W}$ at $250 \mathrm{~K}$. This is the highest value for QDIP devices operated at a temperature beyond $200 \mathrm{~K}$ in the $2.5-7-\mu \mathrm{m}$-wavelength range.

The responsivities of QDIP devices operated at $36 \mathrm{~K}$ are shown in Figs. 4(a) and 4(b). The spectral response at the wavelength range of $2.5-4 \mu \mathrm{m}$ with peak responsivity 25 $\mathrm{mA} / \mathrm{W}$ is observed at zero bias. The responsivity decreases with increasing positive bias and vanishes at $+0.1 \mathrm{~V}$, whereas the increase of responsivity with decreasing negative bias is observed as shown in Fig. 4(c). This is clearly a $\mathrm{PV}$-mode operation. However, in the wavelength range from 3.5 to $7 \mu \mathrm{m}$, the peak responsivity increases with increasing magnitude of external voltage and vanishes at zero bias, which corresponds to a photoconducitivity (PC) -mode operation. The PC-mode peak responsivity is $155 \mathrm{~mA} / \mathrm{W}$ at 5 $\mu \mathrm{m}$ under external voltage $0.42 \mathrm{~V}$. One reason responsible for the asymmetric photoresponse is the segregation of

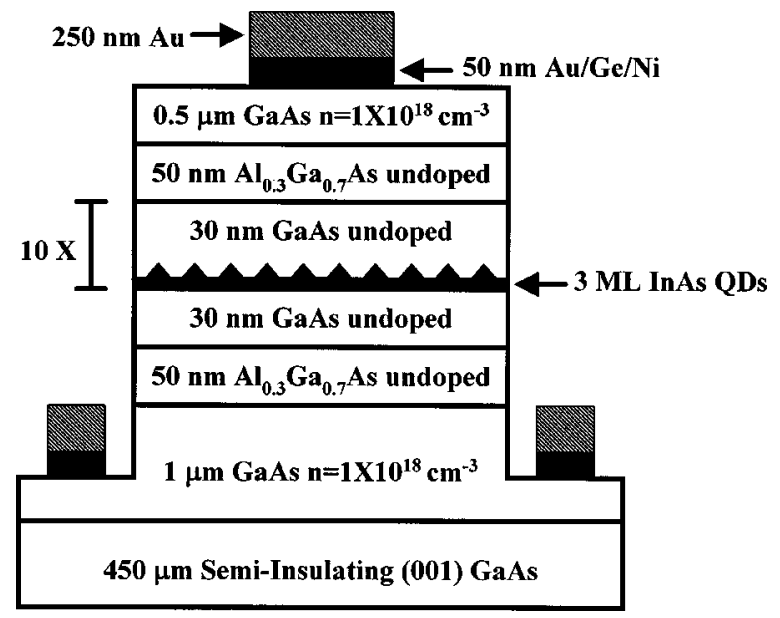

FIG. 1. Schematic doagram showing the structure of the InAs/GaAs QDIP device. 


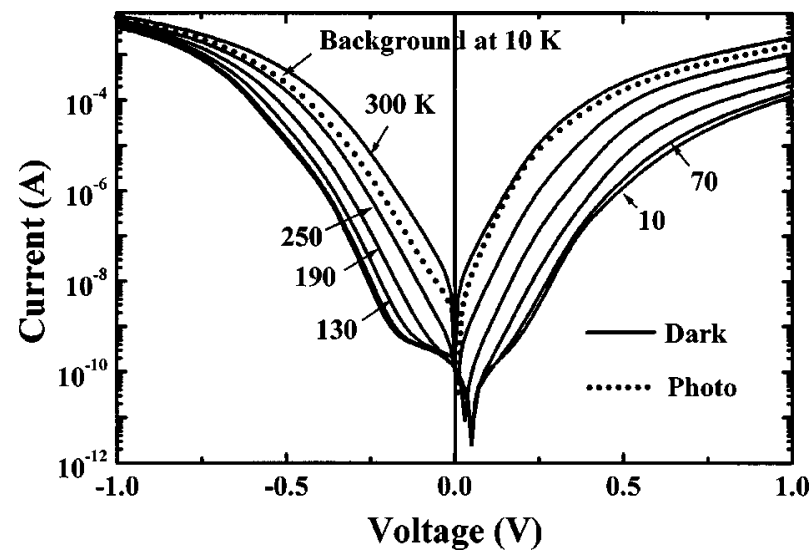

FIG. 2. Dark $I-V$ characteristics of the QDIP device from 10 to $300 \mathrm{~K}$. The dotted curve represents the photocurrent measured at $10 \mathrm{~K}$ when the QDIP is illuminated from the ambient background radiation through the cryostat window.

doped Si toward the top surface of the QD, which results in an asymmetric electric-field distribution. Another possibility would be the asymmetry of the dot shape resulting in the asymmetric response of the QDIP. ${ }^{9}$ The spectral responsivities of the QDIP at $150 \mathrm{~K}$ under positive and negative biases are shown in Figs. 5(a) and 5(b). The dominant mechanism

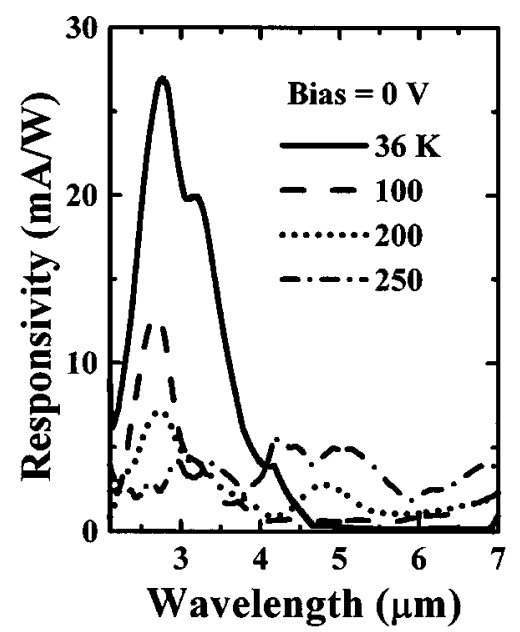

(a)

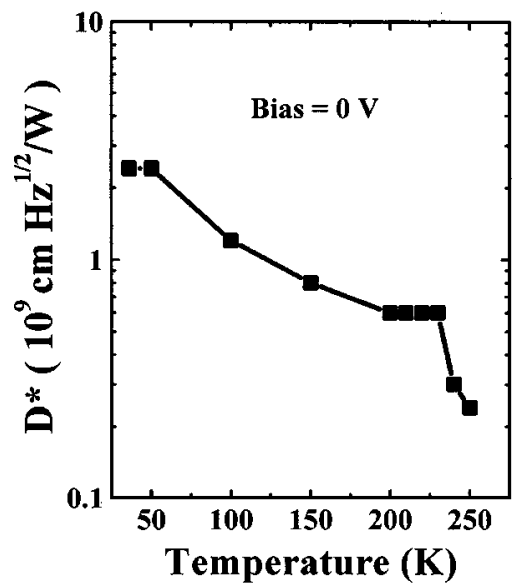

(b)

FIG. 3. (a) Responsivity of the QDIP as a function of temperature at zero bias. (b) Specific detectivity of the QDIP as a function of temperature at zero bias.

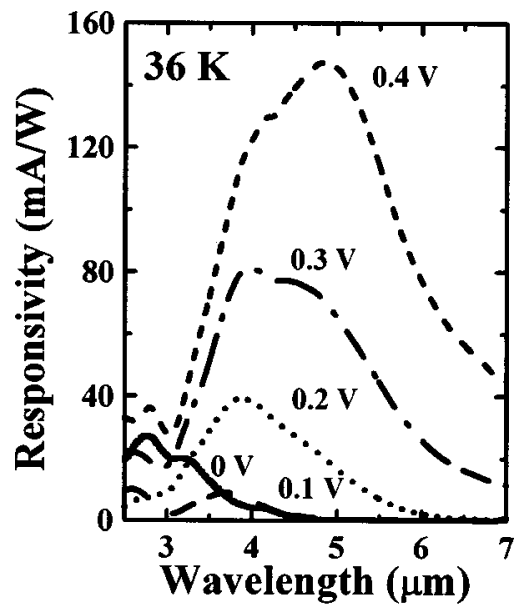

(a)

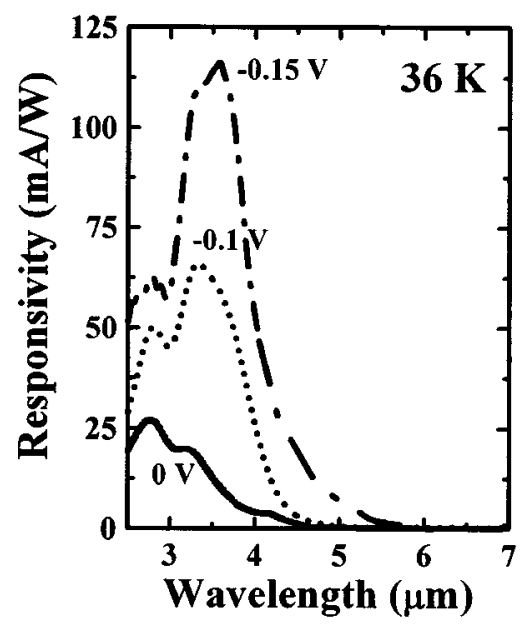

(b)

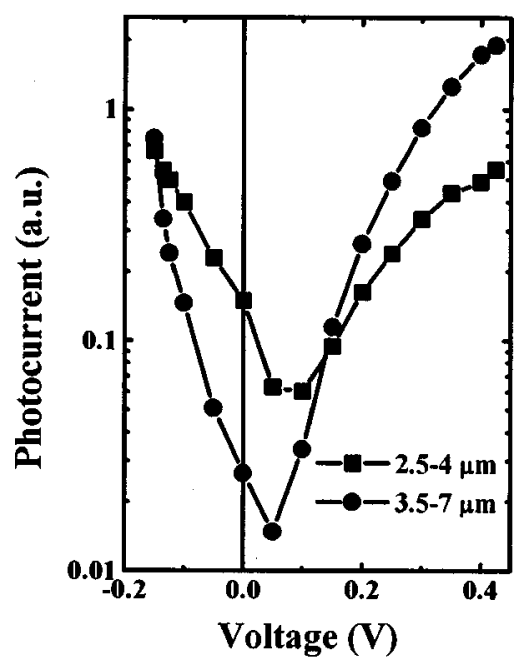

(c)

FIG. 4. Responsivity of the QDIP at $36 \mathrm{~K}$ under (a) positive bias from 0 to $0.4 \mathrm{~V}$ and (b) negative bias from 0 to $-0.15 \mathrm{~V}$. (c) Bias-dependent photocurrent in two different wavelength regions of $2.5-4$ and $3.5-7 \mu \mathrm{m}$.

is the PV-mode operation. The PC-mode response almost disappears due to the large dark current induced by increasing bias. The PC- and PV-mode responses of the device are attributed to two different mechanisms. According to our calculation, there are two energy levels in the InAs quantum dot with conduction-band discontinuity $0.83 \mathrm{eV}$ and dot size 30 


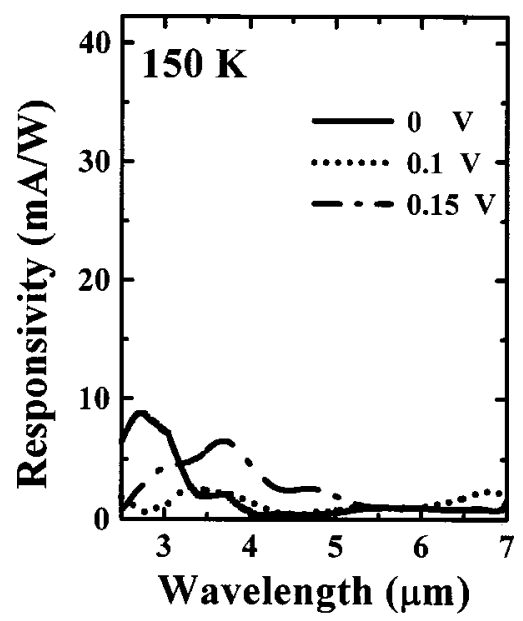

(a)

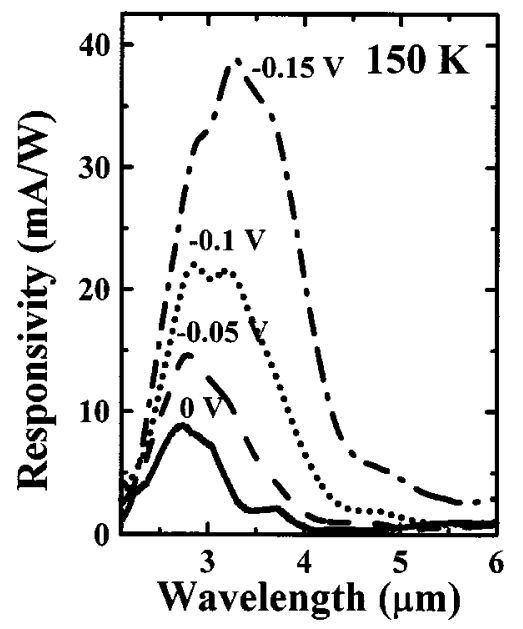

(b)

FIG. 5. Responsivity of the QDIP at (a) positive bias from 0 to $0.15 \mathrm{~V}$, and (b) negative bias from 0 to $-0.15 \mathrm{~V}$. The temperature is $150 \mathrm{~K}$.

$\mathrm{nm}$ in diameter and $6 \mathrm{~nm}$ in height. The locations of the energy levels are 0.15 and $0.63 \mathrm{eV}$ above the conductionband edge. The corresponding wavelengths of the first to second (subsequent tunneling) and the second continuum are
2.5 and $6.4 \mu \mathrm{m}$, respectively, which coincide with the twopeak spectral response of the device. The second excited states were populated with electrons as indicated from curve fitting of temperature-varying dark currents at fixed bias.

A simple model is proposed to explain the mechanism resulting in the high-temperature operation by the QDIP. By measuring the recovery of the resist at $36 \mathrm{~K}$ after the device is shielded from the glowbar, the recovery time constant is found to be extremely long, i.e., $6.64 \mathrm{~s}$, which suggests that the photoexcited electrons are difficult to recapture by QDs unless under rather high temperature. This is the highphotoelectric-gain nature of the QDIP. ${ }^{3}$ The $\mathrm{Al}_{0.3} \mathrm{Ga}_{0.7} \mathrm{As}$ blocking layers reduce the dark current sharply, and the photoelectrons generated from QDs will be confined by these layers and accumulate inbetween. The photocurrent is thus much enhanced, which explain the high-temperature operation of the device.

In conclusion, by clamping the InAs/GaAs QDIP with two blocking barriers, the operation temperature is pushed up to $250 \mathrm{~K}$. Both PC- and PV-mode operations are observed, the peak-specific detectivity $D^{*}$ of $2.4 \times 10^{8} \mathrm{~cm} \mathrm{~Hz}^{1 / 2} / \mathrm{W}$ at $250 \mathrm{~K}$ is achieved.

This work was partly supported by the National Science Council of the Republic of China under Contract No. NSC 89-2215-E-002-018.

${ }^{1}$ S. D. Gunapala, S. V. Bandara, J. K. Liu, W. Hong, M. Sundaram, P. D. Maker, R. E. Muller, C. A. Shott, and R. Carralejo, IEEE Trans. Electron Devices 45, 1890 (1998).

${ }^{2}$ C. J. Chen, K. K. Choi, W. H. Chang, and D. C. Tsui, Appl. Phys. Lett. 72, 7 (1998)

${ }^{3}$ V. Ryzhii, Semicond. Sci. Technol. 11, 759 (1996).

${ }^{4}$ S. Xu, S. J. Chua, T. Mei, X. C. Wang, X. H. Zhang, G. Karunasiri, W. J. Fan, C. H. Wang, J. Jiang, S. Wang, and X. G. Xie, Appl. Phys. Lett. 73, 3153 (1998).

${ }^{5}$ D. Pan and E. Towe, Appl. Phys. Lett. 75, 2719 (1999).

${ }^{6}$ S. Kim, H. Mohseni, M. Erdtmann, E. Michel, C. Jelen, and M. Razeghi, Appl. Phys. Lett. 73, 963 (1998).

${ }^{7}$ J. W. Kim, J. E. Oh, S. C. Hong, C. H. Park, and T. K. Yoo, IEEE Electron Device Lett. 21, 329 (2000).

${ }^{8}$ S. F. Tang, S. Y. Lin, and S. C. Lee, Tech. Dig. Int. Electron Devices Meet. 601 (2000).

${ }^{9}$ D. Pan, E. Towe, and S. Kennerly, Appl. Phys. Lett. 76, 3301 (2000). 